\title{
INSTRUMENTO, CATEGORÍA PARA LA COMPRENSIÓN DEL NUEVO MUNDO
}

\author{
Alberto Saladino García \\ Universidad Autónoma del Estado de México \\ fua_2004@hotmail.com
}

\begin{abstract}
The variety of meanings of the word 'instrument' produced during the XVI century - throughout the works of Bernardino de Sahagún in General History of the Things of New Spain and Francisco Hernández's Antiquities of New Spain-, such as implement utensil, resource to produce or transform things or objects, musical device, sensitive organ, was a key idea to interpret the Indian American reality and its sociocultural manifestations.

Key Words: instrument, implement, utensil, object, New World.
\end{abstract}

\section{Resumen}

La epistemología acerca de la noción de instrumento en el siglo XVI novohispano destacaba la idea de herramienta, utensilio, medio para producir o transformar bienes, aparato musical y órgano de la sensibilidad. De manera explícita, las referencias aparecen recurrentemente en obras como Historia general de las cosas de la Nueva España, de Bernardino de Sahagún, y Antigüedades de la Nueva España de Francisco Hernández, entre otras. Los diversos sentidos del empleo de la noción de instrumento en la centuria de la conquista confluyeron en su consolidación como categoría de interpretación al ser considerada un medio fundamental para coadyuvar a la comprensión de la realidad americana tanto en sus manifestaciones materiales como en las socioculturales.

Palabras claves: aparato, herramienta, instrumento, objeto, realidad, Nuevo Mundo, utensilio.

El uso de la noción de instrumento en el siglo XVI novohispano destacaba ya una pluralidad de referentes como la idea de herramienta, utensilio, aparato, medio para hacer algo u órgano de la sensibilidad; pero

*Recibido: 14-09-07. Aceptado: 11-04-08. 
también fue empleada como categoría orientada a la comprensión de la realidad del Nuevo Mundo.

Obviamente, tal conceptualización forma parte del ambiente cultural que trasladaron los europeos al continente americano durante el siglo de la conquista y en la que el uso de esta categoría les resultó fundamental para explicar la realidad que enfrentaron y buscaron retratar. Consecuentemente, no sólo fue referida en el sentido común de la época, sino que la nueva realidad impactó en su resemantización.

Ciertamente, el contexto cultural dominante en el siglo XVI en el Viejo Mundo matizó en los intelectuales de entonces el empleo de este término, en particular la omnipresencia filosófica de Aristóteles que llevó a que el término instrumento fuera usado como traducción de ópravov, la herramienta lógica para el ejercicio del intelecto, de ahí que, como bien lo expuso Elsa Cecilia Frost, la novedad de la tierra y el ansia de saber, ${ }^{1}$ fueron atendidos gnoseológicamente desde la perspectiva de la filosofía aristotélica, en la que aparentemente nada se añade, empero sí debe considerarse la interpelación que efectúa la realidad americana, la cual explica la resemantización y enriquecimiento que se puede observar en los usos de dicha categoría durante esa centuria.

Mi apreciación sobre la persistencia del legado intelectual del estagirita en el siglo XVI novohispano la sustento principalmente en la traducción de la palabra griega ópravov como instrumento, pues su Tratado de lógica, que entre las partes que lo integran están los Tópicos, cuyo "Libro I. La dialéctica, su concepto, utilidad e instrumento", contiene una referencia explícita, en particular en el capítulo "13. Los instrumentos de la dialéctica” donde expone: “... Ahora bien, los instrumentos a través de los cuales llevaremos a buen término los razonamientos son cuatro: primero, tomar las proposiciones; segundo, poder distinguir de cuántas

\footnotetext{
${ }^{1}$ Elsa Cecilia Frost: "Los intereses filosóficos de Francisco Hernández", en Francisco Hernández: Obras completas. Escritos varios, Tomo VI, México: UNAM 1984, p. 201.
} 
maneras se dice cada cosa; tercero, encontrar las diferencias; cuarto, la observación de lo semejante". 2

Así queda corroborado que el legado aristotélico durante el siglo XVI novohispano animó el uso del término instrumento como medio para comprender la realidad del Nuevo Mundo.

De modo que se puede observar que, en algunas obras escritas en el siglo XVI, es manifiesta la inquietud por apelar al uso racional de la palabra instrumento y, en cierto sentido, hace eco a una semántica más científica que filosófica toda vez que su recurrente empleo, en diversos textos redactados en dicha centuria, invoca a retratar las diversas manifestaciones de la realidad natural y las creaciones culturales.

Para sustanciar estas apreciaciones recurriré a dos obras, por cierto con igual cometido: dar cuenta de la situación sociocultural de la época prehispánica, escritas por personajes ilustres, que las produjeron en el siglo XVI, Bernardino de Sahagún, Historia general de las cosas de Nueva España y Francisco Hernández, Antigüedades de la Nueva España, a la que agregaré algunas referencias de las obras del protomédico intituladas Filosofía natural y Problemas o erotemas filosóficos según la doctrina de los peripatéticos y de su príncipe Aristóteles.

En esos textos aparece el empleo del término instrumento tanto en títulos de apartados y capítulos como en la exposición de contenidos de algunos de ellos, por ejemplo en la obra de Sahagún, el libro nono lo presenta "De los instrumentos con que laboran los oficiales de pluma" y en su adenda, capítulo IV, del arte plumario en uno de sus apartados expone acerca "De los instrumentos con que labran los oficiales de la pluma". Si bien en los escritos de Hernández ningún título del libro, capítulo o apartado usa el vocablo instrumento, es recurrente en la exposición de los temas que aborda.

De ahí que pueda sustentar que la palabra instrumento sea usada en el siglo XVI como sinónimo de herramienta o utensilio; aparato; objeto para producir sonidos musicales; cosa o materia para hacer algo, $\mathrm{u}$

\footnotetext{
${ }^{2}$ Aristóteles: Tratado de lógica (Órganon) I. Categorías, Tópicos, Sobre las refutaciones sofísticas, introd., trad. y notas de Miguel Candel Sanmartín, $3^{\mathrm{a}}$ edición, Madrid: Gredos 1988, p. 109.
} 
órgano de la sensibilidad. Para el efecto ejemplificaré cada uno de esos usos con base en las obras mencionadas.

\section{Instrumento como herramienta o utensilio}

La recurrencia al empleo del concepto instrumento como sinónimo de herramienta o utensilio está presente en la obra de ambos autores. En el caso de Bernardino de Sahagún es abundante y resultan ilustrativos el libro primero, capítulo XVII que habla de Opochtli de quien refiere: "Atribuían a este dios la invención de las redes para pescar peces, y también un instrumento para matar peces que le llamaban minacachalli [...] También éste inventó los lazos para matar las aves y los remos para remar" ; y el libro nono, capítulo XX, intitulado "De los instrumentos con que labran los oficiales de pluma" donde expone:

En esta letra se ponen todos los instrumentos que usaban estos oficiales de la pluma. Y también agora los usan donde quiera que están; por eso no se declara en la lengua española. Quien quisiere verlos y saber sus nombres, de los mesmos oficiales lo podrá saber y verlos con sus ojos ${ }^{4}$.

De hecho, en esta obra existe un uso abundantísimo de la palabra instrumento como herramienta o utensilio, que es el medio de que se valían los artesanos y artistas para producir sus obras, empleadas en todos los ámbitos de la vida social.

Lo mismo puede decirse de Francisco Hernández quien de manera específica lo hace cuando en el capítulo décimo "De los sacerdotes mexicanos" de su libro Antigüedades de la Nueva España, expone:

Desempeñaban el ministerio de Huitzilopochtli cinco mil hombres, pero no todos tocaban o manejaban los altares,

\footnotetext{
${ }^{3}$ Bernardino de SAHAgún: Historia general de las cosas de la Nueva España. Versión íntegra del texto castellano del manuscrito conocido Códice Florentino, Tomo I, Estudio introductoria, paleografía, glosario y notas de Alfredo López Austin y Josefina García Quintana, México: Consejo Nacional para la Cultura y las Artes 2000, p. 97.

${ }^{4}$ SAhagún: Historia general de las cosas de la Nueva España, Tomo II, p. 850.
} 
la herramienta, los vasos y otros instrumentos dedicados a celebrar los sacrificios como eran los braseros que contenían carbones encendidos. Estos eran de diversos tamaños, algunos de oro, otros de plata, pero la mayor parte de barro cocido y de arcilla ${ }^{5}$.

Según se puede apreciar, uno de los significados más recurrentes del término instrumento en el siglo XVI fue el de herramienta, esto es, el medio material con el cual se respalda el trabajo de cualquier oficio, y utensilio, o sea, el objeto de apoyo manual de toda obra u oficio.

En este caso debe destacarse la armonía existente entre instrumento, herramienta y utensilio, pues en verdad — para este primer significadolas fronteras semánticas de dichos términos son tan tenues que hasta resulta conveniente considerarlos intercambiables sin afectar el sentido de las frases donde se usan.

\section{Instrumento como aparato}

El empleo de esta palabra como sinónimo de instrumento tiene la virtud de amplificar su ámbito de aplicación, lo que queda corroborado con la lectura atenta de las obras de los intelectuales que me sirven de referencia, empero aquí sólo referiré su correspondencia con instrumento.

Bernardino de Sahagún identifica el término aparato como equivalente a instrumento al conceptuar aquél como cualquier objeto con el cual se puede hacer algo, pues si se considera la adición al libro nono de su Historia general de las cosas de la Nueva España, capítulo III, suscribe: "26. Y la turquesa, por no ser dura, no más con un poco de arena se pule y perfecciona y con ella también se le puede dar el brillo, darle relucencias; con un instrumento especial que se llama 'pulidor de turquesas"”; 6 igualmente identifica una tablita como "cortador de pa-

\footnotetext{
${ }^{5}$ Francisco Hernández: Obras completas. Escritos varios, Tomo VI, México: UNAM 1984, p. 116.

${ }^{6}$ Bernardino de SAHagún: Historia de las cosas de Nueva España, Edición con numeración, anotaciones y apéndices de Ángel María Garibay, México: Porrúa 1979, p. 526.
} 
lo", ${ }^{7}$ y plegaderas de hueso ${ }^{8}$ que fueron utilizadas por el plumajero en la realización de sus labores.

De paso señalo que fue Sahagún quien empleó el concepto aparato en un sentido más amplio con el cual trasciende el significado de instrumento al referirlo a la sofisticada organización guerrera prehispánica, parte esencial, por ejemplo del estado mexica.

En tanto Francisco Hernández relaciona diversos objetos como aparatos que los antiguos mexicanos empleaban para efectuar sus construcciones como:

$[\mathrm{H}]$ achas, barrenas y escoplos de cobre... Con palo sacan piedra de las canteras y con palo forman con arte maravilloso de la piedra iztlina espadas, sables, instrumentos propios para castrar el maguey, puntas de flechas y dardos y navajas $^{10}$.

Entonces queda comprobado que el campo semántico de instrumento, en el siglo XVI fue amplio porque además de significar herramienta y utensilio denotó aparato, pero tampoco quedó reducido a ellos, como expongo a continuación.

\section{Instrumento, objeto para producir sonidos}

En la obra de Bernardino de Sahagún el uso de la palabra instrumento como objeto musical aparece de manera explícita y abundante ${ }^{11}$. De igual manera, en la obra de Francisco Hernández es recurrente su uso. Basten, para ejemplificarlo, las citas que siguen.

\footnotetext{
${ }^{7}$ SAHAGÚn: Historia de las cosas de Nueva España, p. 531.

${ }^{8}$ SAHagún: Historia de las cosas de Nueva España, p. 535.

${ }^{9}$ SAHAgÚN: Historia de las cosas de Nueva España, p. 469.

${ }^{10}$ HernÁndez: Obras completas..., p. 67.

${ }^{11}$ Incluso para estudiosos de la obra de Bernardino de Sahagún no ha pasado desapercibido el empleo recurrente de este término, por ejemplo así lo consignan Alfredo López Austin y Josefina García Quintana, en la edición que prepararon de la obra del fraile franciscano, al incluirlo en su "Índice analítico" con abundantes referencias, ciertamente redujeron su ámbito semántico a la de aparato musical. SAHAGÚN: Historia de las cosas de Nueva España, Tomo III, p. 1394.
} 
Bernardino de Sahagún informa que la celebración del duodécimo mes, llamado teotelco, la realizaban en su día postrero:

$[\mathrm{P}]$ orque dicen que todos los dioses llegaban entonces. La vigilia de este día, a la noche, hacían encima de un petate de harina de maíz un montecillo muy tupido de la forma de un queso. En este montecillo imprimían los dioses la pisada de un pie, en señal que habían llegado. Toda la noche el principal sátrapa velaba e iba y venía muchas veces a mirar cuando vería la pisada. En viendo el sátrapa la señal de la pisada luego daban voces, diciendo: "Llegado ha nuestro [sic] señor". Luego comenzaban los ministros del cu a tañer cornetas y caracoles, y trompetas y otros instrumentos de los que ellos entonces usaban. Luego que se oían los instrumentos, acudía toda la gente a ofrecer comida en todos los cúes y oratorios ${ }^{12}$.

Con ello se da testimonio del empleo de la palabra instrumento como aparato musical, vinculado a creencias religiosas.

Pero también su uso apelaba al festejo del nacimiento de descendientes de progenitores preclaros, pues luego de algunos días, dice Francisco Hernández, en:

[L]a madrugada lo bañaban y lo secaban; al mismo tiempo ordenaban que los instrumentos resonaran con dulcísima música, para cantar las alabanzas del candidato, con la cual muchos bailaban con suma rapidez [...] Los huéspedes convidados a esta celebridad ya entonces comían [...] y algunos ciudadanos entretanto pulsaban huesos, tímpanos, tibias y otros instrumentos propios de los conciertos musicales y ejercitaban los bailes y danzas ${ }^{13}$.

De modo que son identificados los objetos que producían sonidos armoniosos como instrumentos o aparatos musicales.

\footnotetext{
${ }^{12}$ SAhagún: Historia de las cosas de Nueva España, Tomo I, p. 157.

${ }^{13}$ Hernández: Obras completas..., p. 70.
} 
Como es del dominio de los mexicanos, el empleo de los objetos con los cuales producir sonidos musicales fue recurrente en las efemérides prehispánicas y, según se ha dicho antes, sucedió con la alegría de los recién nacidos, también se recurrieron a ellos en la alegría de la muerte como lo señala el mismo Francisco Hernández al comentar los ofrecimientos de sacrificios humanos en "muchas ceremonias, de nuevo mataban algunos cautivos junto al templo de Hoitzilopochtli con otro no pequeño grupo de esclavos celebraban la muerte de cada uno de ellos pulsando los instrumentos patrios"14.

Con base en lo expuesto puede sustentarse que el campo semántico de la palabra instrumento no varió, pues en los tres tipos de significado explicados coinciden intelectuales que vivieron en la primera mitad y en la segunda mitad del siglo XVI, empero sí pueden destacarse variantes, según se fundamenta en los dos usos desarrollados a continuación.

\section{Instrumento, cosa que sirve para hacer algo}

En la obra de Bernardino de Sahagún, aunque parezca reiterativo, es factible evidenciar la amplificación del uso del concepto instrumento durante el siglo de la conquista al identificar con él cosas u objetos útiles al artesano en su cotidiana labor de transformarlos como para ejecutar la acción de transformar.

Las evidencias al respecto se pueden extraer de su obra multicitada, en particular el capítulo XX de su libro nono que tituló, como ya anticipé: "De los instrumentos con que labran los oficiales de la pluma", al igual que su adenda sobre el arte plumario, en donde explica:

$\mathrm{Y}$ aquellos con que cortaban eran navajas de obsidiana a las cuales agregaban un madero de sabino (ahuéhuetl), sobre el cual cortaban la pluma [...] Entonces poco a poco, fueron descubriendo, fueron inventando, fueron poniendo en uso todos sus instrumentos de trabajo ${ }^{15}$.

\footnotetext{
${ }^{14}$ HeRnÁndeZ: Obras completas..., p. 153.

${ }^{15}$ SAHAGÚN: Historia de las cosas de Nueva España, p. 529.
} 
Por tanto, objetos para transformar y medios materiales de transformación también fueron identificados con la palabra instrumento.

\section{Instrumento como órgano de los sentidos}

Por su formación médica, Francisco Hernández extendió el uso del concepto instrumento más allá de cosas materiales, al emplearlo en la explicación de las sensaciones.

Por ejemplo, cuando habla del sentido de la vista en su libro Quinto del ánima, plantea:

Podría alguno dudar por qué no vienen a la vista las cosas sino solo su semejanza, pero es cierto no poderse sentir lo que fuera desto se siente si lo ponen sobre los instrumentos de los sentidos, antes estorbar la obra del sentimiento, por lo cual es necesario que la luz, color y lumbre, envíen si se han de ver sus especies a los sentidos, lo cual si pansa así, cuatro cosas serán menester para sentir cualquiera cosa. Conviene a saber: objecto, medio, instrumento y espíritu ${ }^{16}$.

Más adelante precisa que sin instrumentos, esto es, sin órganos, no existe sensación y que su existencia misma requiere los cuatro elementos citados.

Entonces la categorización del término instrumento en la Nueva España coadyuvó, durante el siglo de la conquista, a matizar y resignificar su ámbito semántico toda vez que hizo referencia a cualquier medio para el trabajo; a todo objeto útil para transformar materiales; a los objetos productores de sonidos musicales; a los órganos de la sensibilidad, e incluso fue empleado para referir elementos y factores de la organización guerrera.

Con base en ese ramillete de significados puede inferirse que el uso recurrente de la categoría instrumento en el siglo XVI adquirió una función gnoseológica incuestionable pues sirvió para revelar la realidad del

\footnotetext{
${ }^{16}$ HeRnÁndEZ: Obras completas..., p. 258.
} 
Nuevo Mundo, para comprender, conocer y explicar sus manifestaciones naturales y las creaciones culturales de las sociedades prehispánicas en el inicio del periodo novohispano. De modo que así inició su consolidación como categoría de interpretación, mas con una pluralidad de significados. 